\title{
Prediction of Psychosocial Adjustment Using Psychological Wellbeing and Coping Strategies in Patients Suffering from Lymphoma Cancer and Leukemia
}

\author{
Laila Khalighi Delavar
}

M. A in Clinical Psychology, Science and Research Branch, Islamic Azad University, Karaj, Iran

Fahimeh Rahmati

M. A in Clinical Psychology, Science and Research Branch, Islamic Azad University Guilan, Iran

Mina Asgari Parvar

M. A in Clinical Psychology, Science and Research Branch, Islamic Azad University Sari, Iran

Nila Pour Darsaraie

M. A in Clinical Psychology, Science and Research Branch, Islamic Azad University Guilan, Iran

\section{Doi:10.5901/mjss.2014.v5n20p3123}

\section{Abstract}

\begin{abstract}
The present research tries to predict psychosocial adjustment based on psychological wellbeing and coping strategies in patients suffering from Lymphoma cancer and Leukemiain Tehran, Karaj and Rasht Cities. This research was conducted in 2013 and 2014. Using accessible sampling method, 200 patients who suffered from Lymphoma cancer and Leukemia (93 cancer patients and 107 Leukemia patients) were selected. In order to evaluate research variables, psychosocial adjustment questionnaire in chronic patients, Reef's psychological wellbeing questionnaire and Andler\&Parker's questionnaire of coping strategies in stressful conditions were used. Multivariate regression analysis revealed that task-oriented coping strategies predict $14 \%$ of variations in psychosocial adjustment, emotion-oriented coping strategies predict $26 \%$ and avoidant coping strategies predict $23 \%$ and psychological wellbeing predicts $24 \%$ of variations in psychosocial adjustment variable. According to the results of the research, it can be said that task-oriented coping strategies and psychological wellbeing act like a dampener against stressful factors and chronic diseases. Moreover, psychological wellbeing acts as a positive factor in cancer patients and improves their psychosocial adjustment.
\end{abstract}

Keywords: psychosocial adjustment, psychological wellbeing, coping strategies.

\section{Introduction}

Cancer is the second death factor across the world. Patients experience cognitive changes during disease period in order to understand different aspects of disease, finding a sense of overcoming and maintaining their self-confidence. Experience of a chronic disease involves adjustment in different life areas. Stress and anxiety are embedded in human life in today's complex world. Within the recent years, a group of positivist psychologists have defined psychological health as a positive psychological performance and have conceptualized it as "psychological wellbeing". This group believes that satisfaction with life, appropriate progress, efficient interaction and association with other people and interaction with the world are characteristics of a healthy individual (Mikaeeli Mani, 2010). One of the personality features which is effective in psychological wellbeing is the way an individual copes with tension. Coping styles are defined as active and purposeful processes of responding to difficult and tense situations (Khodayarifard, 2010). Experience of chronic diseases involves adjustment in different life areas. Chronic diseases like cancer cause unique types of stress in patients and their families. Such patients consider cancer as their real murderer and something that brings severe pain and disability. A patient's adjustment and his/her compatibility and way of dealing with the disease affect the results of treatment and improvement trend (Drogits, 2002). Blood cancer or Leukemia is a progressive and malignant disease of blood-producing organs of body. Lymphomas are a group of cancers which affect security system cells especially lymphatic system cells. They are classified in two categories: Hodgkin and non-Hodgkin. These two disease differ in the 
type and origin of the malignant cell (Akbarzadeh Pasha, 2010). People try to establish balance with internal and external problems. This way of confrontation with life problems is known as adjustment. Some believe that adjustment is stable cognitive changes that occur in an individual in confronting with internal and external stressful factors. Chronic diseases like cancer cause unique types of stress in patients and their families.A patient's adjustment and his/her compatibility and way of dealing with the disease affect the results of treatment and improvement trend (Drogits, 2002). An individual's belief about him or her and another person and other people and his or her interactions with this triangle specifies his or her adjustmentlevel and predicts his or her ability to cope with stressful conditions like cancer (Munoz Eiguiletal, 2007). Vising (1988) and Vandan (1994) introduces a general psychological wellbeing construct which is characterized and evaluated by means of "sense of integration and cohesion "in life, emotional balance and general satisfaction with life. They emphasize that psychological wellbeing is a multidimensional construct which includes the following areas:

1. emotion: positive feelings overcome negative feelings in healthy people.

2. cognition: healthy individuals experience satisfaction with life. They feel life is understandable and controllable.

3. behavior: healthy individuals accept life challenges and are interested in work and activity.

4. inter-personal relationships: healthy individuals trust in others and are good at social interactions (as quoted from Mikaeeli Mani, 2009). Effective coping is an important resource for creating a good feeling and psychological adjustment in stressful situations and influences on physical and psychological health. Emotions are adjusted and stresses are removed if effective coping strategies are utilized. Effective coping styles reduce negative impacts of stress and increase ability to cope with environmental stressors. This is while ineffective coping strategies increase negative impacts of stress. Good problem-solving ability, enough experiences, access to appropriate support systems, good sleep and hygiene and balanced lifestyle are factors affecting effective coping styles. Individuals who are not able to cope effectively experience more stress and absence of adjustment results in psychological disorders and problems. Many psychological problems are resulted from ineffective coping methods. If individuals use effective coping strategies, they get adjusted to environmental changes. Khodayarifard et al (2010) conducted a research titled "relationship between life quality, coping strategies and worry about death among cancer survivors. The research was a correlation study which used accessible sampling and involved 30 cancer patients and 30 cancer survivors. Results of studies showed that there is a significant relationship between life quality and cancer survivors $(p=0.01)$. moreover, there was a significant relationship $(\mathrm{p}=0.01)$ between task-oriented coping style, cancer survivors and cancer death. Further, there was a significant difference between task-oriented coping strategy and emotion-oriented coping strategy in patients who suffered from cancer and cancer survivors $(\mathrm{p}=0.05)$. Roni et al (2003) found that there is a negative and significant relationship between dimensions of psychological wellbeing, anxiety, depression and aggression. In a review study conducted by Park and Gaffey (2007) on adjustment and teenagers' and children's coping strategies afflicted with cancer, results showed that internal control can facilitate positive behavioral changes. Kariv and Heiman (2009) also showed that coping strategy along with control resource is the most important predictor of tension in mothers and fathers. Pakenham and Jim (2009) showed that MS patients use task-oriented coping styles less than healthy individuals and mostly use emotion-oriented coping styles. Results of studies conducted by other researchers showed that psychosocial interventions are effective in depression, anxiety and life quality of cancer patients. Cancer patients are confronted with problems in the three dimensions of life quality (physical, psychological and social) and psychological interventions along with medical treatments can be effective in improvement of life quality. In another research, Okun and Stock (2009) found that religious beliefs and physical health are two strong predictors of psychological wellbeing in cancer patients. Stronger and more significant correlations are usually based upon real religious behavior and not religious attitudes. In other words, individuals who take part in activities related to religious faith (like attendance at church and saying prayers) usually have higher levels of wellbeing in comparison to those who have pure religious attitudes. In another research, survival of cancer patients who had taken part in weekly group meetings led by a therapist survived from cancer was investigated. These meetings allowed patients to talk about their feelings and their adjustment method and learn about self-hypnotism methods used for reducing pain. In comparison with control group, patients who had used psychosocial interventions lived on about 18 months on average (Spiegel et al, 2011). Moreira and Canavaro (2013) compared psychosocial adjustment and couples' intimacy in sexual partners of women who suffered from breast cancer and sexual partners of women who did not suffer from breast cancer. In this study, 70 men whose wives suffered from breast cancer were compared with 70 men whose wives did not suffer from breast cancer. Further, the role of couples' intimacy in psychological adjustment and the mediating role of group type were investigated. Results showed that partners of women who suffered from breast cancer had high levels of anger and anxiety and depression symptoms. Investigations showed that interest and intimacy of couples in partners of women suffering from cancer is a good predictor of depression and anxiety and life quality. Pettet (2013) investigated the impact of spiritual and religious attitude on cancer treatment. He 
showed that spiritual and religious beliefs affect cancer treatment considerably. Further, his results showed that measurement of spirituality and wellbeing has a significant relationship with life quality of cancer patients and cancer survivors. This study revealed that when therapists and nurses use spiritual cares for patients, they express higher levels of psychological adjustment. Kurita et al (2013) conducted a research titled absence of psychosocial adjustment in lung cancer patients. The sample included 50 patients who had received 6 months of treatment. Investigations showed that weak psychological wellbeing and high understanding of stress are related to high levels of absence of adjustment and confidence. Non-somatic depression symptoms have significant relationship with absence of confidence. In fact, avoidance plays the role of a mediator between absence of adjustment and low psychosocial adjustment. Zainal and Saniah (2010) conducted a research titled: "anxiety and depression and coping styles in breast cancer patients receiving chemical-therapy. The sample included 141 people of patients who suffered from breast cancer. Their average age was $m=50$. Anxiety spread was $24 \%$ and depression spread was $19 \%$. Patients who had anxiety symptoms showed higher points in avoidance and absence of behavioral participation in comparison with patients who did not have any sign of anxiety. Further, patients who had symptoms of depression showed higher points in self-criticism and isolation in comparison with patients who did not show any symptom of depression. Malak et al (2011) conducted a research titled: "relationship between psychosocial adjustment and hopelessness in women suffering from breast cancer". They studied 90 breast cancer patients who received radio-therapy and chemical-therapy in a super-specialized hospital in Turkey. Their average age was 49.4 -+ 11. About $63.3 \%$ of them showed low level of psychosocial adjustment. Results showed that results of this research showed that as psychosocial adjustment level is lower, hopelessness increases considerably. Therefore, considering the above discussion, the present research predicts psychosocial adjustment using psychological wellbeing and coping styles.

\section{Methodology}

\subsection{Research design}

The present research is a correlation survey.

\subsection{Statistical population and sample:}

Statistical population of the research included all individuals who suffered from Lymphoma and Leukemia and referred to Tehran Shariati hospital, ValiAsr hospital of Tehran Imam Khomeini Complex, central Karaj Clinic, Rasht Razi Hospital and specialized Cancer Clinic of Rasht in 2013. 200 patients who referred to the mentioned hospitals were selected as sample size. 50 patients who suffered from Hodgkin cancer, 50 patients who suffered from non-Hodgkin cancer, 50 patients who suffered from acute Lymphoma and 50 patients who suffered from chronic Lymphoma were selected by means of accessible sampling. 7 questionnaires were incomplete and 4 participants did not cooperate and were set aside. After corresponding with the mentioned hospitals, the questionnaires were distributed among Lymphoma and Leukemia patients. Sample members were all receiving treatment period. First, respondents were familiarized with research objectives and then, they were asked to fill the questionnaires.

Criteria for participation in the survey included:

- diagnosis by an oncologist physician

- $\quad$ Age between 18 to 45

- Absence of psychological interventions over the last year

Criteria for not taking part in the survey included:

- $\quad$ Absence of tendency to cooperate in spite of primary agreement

- Absence of Iranian citizenship

\subsection{Research instrument}

Psychosocial adjustment to illness scale (PAIS):

This scale contains 46 questions on a 4-step scale including 7 areas: health care orientation, occupational environment, house environment, sexual relationships, family relations, social environment and psychological distress (Drofits, 1990; as quoted from HoseinzadehBazargan, 2010). In the original study, Cronbach's alpha coefficients for dimensions were equal to: $0.47,0.76,0.77,0.83,0.62,0.80,0.85$, respectively. Moreover, reliability coefficients for breast 
cancer patients were equal to $0.74,0.68,0.61,0.86,0.56,0.82$, and 0.84 , respectively. Construct validity of this scale was analyzed with exploratory factor analysis and Varimax Rotation. Results showed that these 7 dimensions predict 0.63 of the variance of all scale and each sub-construct predicts $0.18,0.10,0.9,0.8,0.7,0.7$, and 0.5 of total variables respectively. Correlation of each sub-scale with total point in cancer patients was equal to $0.56,0.60,0.83,0.52,0.47$, 0.83 , and 0.74 , respectively. Convergent validity of total point and each of the sub-scales with general indices of SCL 90 were equal to $0.60,0.34,0.39,0.45,0.13,0.57,0.30,0.83$. in general, PAIS has a good reliability and validity.in the present research, Cronbach's alpha coefficients for subscales of this scale were equal to $0.72,0.7,0.63,0.87,0.59,0.8$, and 0.85 , respectively. The lowest point was 46 and the highest point was 184 . A low point in this scale is indicative of higher psychosocial adjustment. Patients' adjustment is evaluated by means of their points in psychosocial adjustment scale (as quoted from HoseinZadehBazargan, 2010).

Reef's Scales Psychological wellbeing test (RSPWB):

This scale (1989) was designed by Reef and revised in 2002. In Iran, Niknam first translated it into Persian and used it (Mikaeeli Mani, 2010). This scale has 6 factors:

1. self-acceptance: positive attitude to oneself and acceptance of one's positive aspects like good and bad characteristics and positive sense about past.

2. positive communications with others: sense of satisfaction and intimacy with relationships and understanding the importance of dependences.

3. autonomy: sense of independence and effectiveness in life events and active role in behaviors.

4. domination over environment: a sense of domination over environment, control of external activities and effective use of surrounding opportunities.

5. purposeful life: having targets in one's life and belief in one's significant past and future.

6. individual growth: a sense of continuous growth and achieving new experiences as a creature having potential talents.

The sum of the points of the above 6 factors is total point of psychological wellbeing. This test is a self-evaluation instrument in which the questions are designed on a 6-point scale from "completely agree" to "completely disagree" (1 to 6). 44 questions are directly scored and 40 questions are reversely scored (Mikaeeli Mani, 2010).

This scale was first implemented on 231 people and internal consistency coefficient of the scales was between 0.86 and 0.93 and retest reliability coefficient after 6 weeks on 117 people was between 0.81 and 0.86 . further, correlation between subscales was between 0.32 and 0.76 . the highest correlation was between self-acceptance and domination over environment (0.76) and the lowest correlation was between autonomy and positive relationship with others (0.32) (Bayani, Mohammad Koucheki, 2007). Reef (1989) investigated evidence from test validity by calculating correlation coefficient of the points of psychological wellbeing scale and the points of tests that measured psychological positive performance (convergent validity) and negative psychological performances (divergent or discriminant validity). Results showed that there is a positive and significant correlation between 6 factors of this questionnaire and tests which evaluate positive psychological performances (like Vewgarten's life satisfaction index, Rozenberg's self-esteem index, Vevinson's internal control index, Bradborn's emotional balance and Lovton's ethics scale) $(p<0.001)$. Correlationrange was between 0.25 and 0.73 which verified scale validity. He also showed that the 6 factors are independent of each other but have internal consistency $(\mathrm{p}<0.001)$. Correlation domain was between 0.32 and 0.76 and they measured a unit construct named "psychological wellbeing" (Bayani, Mohammad Koucheki, 2007).

Coping inventory for stressful situation (CISS):

This questionnaire was designed by Andler and Parker (1990) and translated by Akbarzadeh (1997). This test contains 48 items on a five-point Likert scale from 1(never) to 5 (always). CISS investigates three main styles of coping stress i.e. task-oriented style, emotion-oriented style and avoidance-oriented style. Each style has 16 items. Points range of each subscale (task-oriented, emotion-oriented and avoidance-oriented) was between 16 and 80 . This questionnaire is a self-reporting instrument. Sum of the points of each construct's questions yields the total point of the construct. Sum of the points of each style specifies the style which is used most. Individuals who acquire similar points in two styles specify their dominant style. Considering the fact that validity and reliability of coping inventory has been investigated and verified in Iran, there was no need to measure it in the present research (Ghoreishi Rad, 2010).

CISS covers three coping styles:

1. task-oriented coping style or active confrontation with problems in order to manage and solve them.

2. emotion-oriented coping style or concentration on emotional responses to a task.

3. avoidance coping style or evasion from a problem.

If a respondent does not answer 5 or less than 5 questions, researcher can mark fifth choice in these questions but 
if he or she leaves more than 5 questions non-responded, that questionnaire is not scored (Ghoreishi Rad, 2010).

In order to obtain reliability of CISS in students, Cronbach's alpha coefficient was used. Alpha was equal to 0.92 for boys and 0.85 for girls (task-oriented), 0.82 for boys and 0.85 for girls (emotion-oriented) and 0.85 for boys (avoidance) and 0.82 for girls (avoidance). Reliability coefficient for total questionnaire was calculated to be equal to 0.8133 . Pearson correlation coefficient was used for calculation of correlation of the CISS factors (as quoted from Ghoreishi Rad, 2010).

- Task-oriented: 0.58

- Emotion-oriented: 0.55

- Avoidance: 0.98

\section{Results}

In order to investigate data, descriptive statistics (frequency, mean, percentage and SD) and inferential statistics were used. Multivariate regression analysis was used to predict each variable out of other variables. Independent $t$ test was used to compare the two groups.

\subsection{Descriptive statistical analysis}

\subsubsection{Demographic results}

Table 1: frequency distribution, percentage, means and SD in patients who suffer from Lymphoma and Leukemia based on gender

\begin{tabular}{|c|c|c|c|c|c|c|}
\hline \multicolumn{2}{|c|}{ total } & \multicolumn{2}{c|}{ Lymphoma patients } & \multicolumn{2}{c|}{ Leukemia patients } & \multirow{2}{*}{ group } \\
percentage & frequency & percentage & frequency & percentage & frequency & gender \\
\hline 69 & 136 & 67.4 & 62 & 70.5 & 74 & male \\
\hline 31 & 61 & 32.4 & 30 & 29.5 & 31 & female \\
\hline 100 & 200 & 100 & 93 & 100 & 107 & total \\
\hline
\end{tabular}

According to table above, Lymphoma patients and Leukemia patients are similar in terms of gender and it can be seen that 0.69 of the respondents are male and 0.31 are female.

\subsection{Inferential analysis}

\subsubsection{Main hypothesis}

Coping styles and psychological wellbeing predict psychosocial adjustment in Lymphoma and Leukemia patients.

Table 2: multivariate regression between coping styles and psychological wellbeing and psychosocial adjustment in Lymphoma and Leukemia patients

\begin{tabular}{|c|c|c|c|c|c|}
\hline \multirow{2}{*}{$\begin{array}{l}\text { Regression } \\
\text { coefficient (B) }\end{array}$} & \multirow{2}{*}{$\begin{array}{c}\text { Ratio F } \\
\text { Probability } P\end{array}$} & \multirow{2}{*}{$\begin{array}{l}\text { Determination } \\
\text { coefficient RS }\end{array}$} & \multirow{2}{*}{$\begin{array}{c}\text { Multiple } \\
\text { correlationMR }\end{array}$} & \multicolumn{2}{|c|}{ Statistical indices } \\
\hline & & & & Independent variable & Dependent variable \\
\hline $\begin{array}{c}B=0.141 \\
T=1.98 \\
=0.049 P\end{array}$ & \multirow{4}{*}{$\begin{array}{l}23.25=F \\
0.000=P\end{array}$} & \multirow{4}{*}{0.323} & \multirow{4}{*}{0.568} & $\begin{array}{l}\text { Task-oriented coping } \\
\text { style }\end{array}$ & \multirow{3}{*}{$\begin{array}{l}\text { Psychosocial } \\
\text { adjustment }\end{array}$} \\
\hline $\begin{array}{l}\mathrm{B}=0.263 \\
\mathrm{~T}=-3.614 \\
=0.000 \mathrm{P}\end{array}$ & & & & $\begin{array}{l}\text { emotion-oriented coping } \\
\text { style }\end{array}$ & \\
\hline $\begin{array}{c}0.239=B \\
T=3.63 \\
=0.000=P\end{array}$ & & & & avoidant coping style & \\
\hline $\begin{array}{c}\mathrm{B}=0.240 \\
\mathrm{~T}=3.081 \\
=0.000 \mathrm{P}\end{array}$ & & & & Psychological wellbeing & \\
\hline
\end{tabular}


Results of the above table indicate the predicting power of coping styles and psychological wellbeing using multivariate regression analysis. Investigations show that the predicting variables can predict 0.56 of variations in psychosocial adjustment. Predicting variables show that task-oriented coping style can predict $14 \%$, emotion-oriented coping style predicts 26\%, avoidance coping style predicts 23\% and psychological wellbeing predicts $24 \%$ of variations in psychosocial adjustment variable in $95 \%$ certainty.

First subsidiary hypothesis: coping styles predict psychosocial adjustment in Lymphoma cancer patients.

Table 3: multivariate regression table for coping styles and psychosocial adjustment in Lymphoma cancer patients

\begin{tabular}{|c|c|c|c|c|c|}
\hline \multirow{2}{*}{$\begin{array}{l}\text { Regression } \\
\text { coefficient (B) }\end{array}$} & \multirow{2}{*}{$\begin{array}{c}\text { Ratio F } \\
\text { Probability P } \\
\end{array}$} & \multirow{2}{*}{$\begin{array}{l}\text { Determination } \\
\text { coefficient RS }\end{array}$} & \multirow{2}{*}{$\begin{array}{c}\text { Multiple } \\
\text { correlation }\end{array}$} & \multicolumn{2}{|c|}{ Statistical indices } \\
\hline & & & & Dependent variable & Dependent variable \\
\hline $\begin{array}{c}B=0.295 \\
T=3.00 \\
p=0.003\end{array}$ & \multirow{3}{*}{$\begin{array}{l}=11.3 \mathrm{~F} \\
p=0.000\end{array}$} & \multirow{3}{*}{0.277} & \multirow{3}{*}{0.256} & Task-oriented coping style & \multirow{3}{*}{$\begin{array}{c}\text { Psychosocial } \\
\text { adjustment }\end{array}$} \\
\hline $\begin{array}{c}B=-0.304 \\
T=-3.17 \\
p=0.002\end{array}$ & & & & $\begin{array}{l}\text { emotion-oriented coping } \\
\text { style }\end{array}$ & \\
\hline $\begin{array}{c}B=0.241 \\
T=2.41 \\
p=0.018\end{array}$ & & & & avoidant coping style & \\
\hline
\end{tabular}

Results of the above table show the ability of coping styles to predict psychosocial adjustment in Lymphoma cancer patients using multivariate regression.

Investigations show that predicting variables can predict 0.52 of variations in psychosocial variable. Task-oriented style can predict $29 \%$ of variations, emotion-oriented style can predict $30 \%$ of variations and avoidance style can predict $24 \%$ of variations in psychosocial adjustment.

Second subsidiary hypothesis: psychological wellbeing can predict psychosocial adjustment in Lymphoma cancer patients.

Table 4: single-variable regression between psychological wellbeing and psychosocial adjustment in Lymphoma patients

\begin{tabular}{|c|c|c|c|c|c|}
\hline $\begin{array}{c}\text { Regression coefficient (B) } \\
\text { Dependent variable }\end{array}$ & $\begin{array}{c}\text { Ratio F } \\
\text { Probability P }\end{array}$ & $\begin{array}{c}\text { Determination } \\
\text { coefficient RS }\end{array}$ & $\begin{array}{c}\text { Multiple } \\
\text { correlation }\end{array}$ & \multicolumn{2}{|c|}{ Statistical indices } \\
\cline { 5 - 6 } & $\mathrm{B}=0.41$ & $\mathrm{~F}=18.97$ & & & \\
$4.35=\mathrm{t}$ & & 0.17 & 0.41 & Psychological wellbeing & $\begin{array}{c}\text { Psychosocial } \\
\text { adjustment }\end{array}$ \\
$0.000=\mathrm{P}$ & $0.000=\mathrm{P}$ & & & & \\
\hline
\end{tabular}

Results of the above table indicate the ability of psychological wellbeing to predict psychosocial adjustment in Lymphoma cancer patients using single-variable regression. Investigations show that psychological wellbeing can predict 0.41 of variations in psychosocial adjustment.

Third subsidiary hypothesis: coping styles can predict psychosocial adjustment in Leukemia cancer patients.

Table 5: multivariate regression between coping styles and psychosocial adjustment in Lymphoma patients

\begin{tabular}{|c|c|c|c|c|c|}
\hline \multirow{2}{*}{$\begin{array}{l}\text { Regression coefficient (B) } \\
\text { Dependent variable }\end{array}$} & \multirow{2}{*}{$\begin{array}{c}\text { Ratio F } \\
\text { Probability } P\end{array}$} & \multirow{2}{*}{$\begin{array}{l}\text { Determination } \\
\text { coefficient RS }\end{array}$} & \multirow{2}{*}{$\begin{array}{c}\text { Multiple } \\
\text { correlation }\end{array}$} & \multicolumn{2}{|c|}{ Statistical indices } \\
\hline & & & & Dependent variable & Dependent variable \\
\hline $\begin{array}{c}=0.171 \mathrm{~B} \\
=1.88 \mathrm{t} \\
=0.062 \mathrm{P}\end{array}$ & \multirow{3}{*}{$\begin{array}{l}F=16.4 \\
P=0.000\end{array}$} & \multirow{3}{*}{0.305} & \multirow{3}{*}{0.570} & $\begin{array}{l}\text { Task-oriented coping } \\
\text { style }\end{array}$ & \multirow{3}{*}{ Psychosocial adjustment } \\
\hline $\begin{array}{l}=-0.45 \mathrm{~B} \\
=-5.31 \mathrm{t} \\
\mathrm{P}=0.000\end{array}$ & & & & $\begin{array}{l}\text { emotion-oriented } \\
\text { coping style }\end{array}$ & \\
\hline $\begin{array}{c}=0.26 \mathrm{~B} \\
=2.93 \mathrm{t} \\
\mathrm{P}=0.004\end{array}$ & & & & avoidant coping style & \\
\hline
\end{tabular}


Results of the above table show the ability of coping styles to predict psychosocial adjustment in Lymphoma cancer patients using multivariate regression. Investigations show that predicting variables can predict 0.57 of variations in psychosocial adjustment. Emotion-orientedcoping style can predict $45 \%$ of variations and avoidant coping style predicts $26 \%$ of variations in psychosocial adjustment.

Fourth subsidiary hypothesis: psychological wellbeing can predict psychosocial adjustment in Lymphoma cancer patients.

Table 6: single-variable regression between psychological wellbeing and psychosocial adjustment in Lymphoma patients

\begin{tabular}{|c|c|c|c|c|c|}
\hline $\begin{array}{c}\text { Regression } \\
\text { coefficient (B) }\end{array}$ & $\begin{array}{c}\text { Ratio F } \\
\text { Probability P }\end{array}$ & $\begin{array}{c}\text { Determination } \\
\text { coefficient RS }\end{array}$ & $\begin{array}{c}\text { Multiple } \\
\text { correlation MR }\end{array}$ & \multicolumn{2}{|c|}{ Statistical indices } \\
\cline { 5 - 6 } & Independent variable & Dependent variable \\
\hline $\begin{array}{c}0.508=\mathrm{B} \\
=6.054 \mathrm{t}\end{array}$ & $36.54=\mathrm{F}$ & 0.258 & 0.508 & Psychological wellbeing & Psychosocial adjustment \\
$0.000=\mathrm{P}$ & $0.000=\mathrm{P}$ & & & \\
\hline
\end{tabular}

Results of the above table show the ability of psychological wellbeing to predict psychosocial adjustment in Lymphoma patients using single-variable regression. Investigations show that the predicting variables can predict 0.508 of variations of psychosocial adjustment.

Fifth subsidiary hypothesis: psychosocial adjustment, coping styles and psychological wellbeing are different in patients suffering from Lymphoma and Leukemia.

Table 7: independent $t$ test table for comparison of mean value of psychosocial adjustment, coping styles and psychological wellbeing in patients who suffer from Lymphoma and Leukemia

\begin{tabular}{|c|c|c|c|c|c|c|c|}
\hline Sig. & df & T value & SD & mean & frequency & groups & variable \\
\hline \multirow[t]{2}{*}{0.234} & \multirow[t]{2}{*}{198} & \multirow[t]{2}{*}{-0.988} & 15.31 & 110.9 & 107 & Lymphoma patients & \multirow[t]{2}{*}{ Psychosocial adjustment } \\
\hline & & & 16.34 & 113.1 & 93 & Leukemia patients & \\
\hline \multirow[t]{2}{*}{0.65} & \multirow[t]{2}{*}{198} & \multirow[t]{2}{*}{0.446} & 11.63 & 61.72 & 107 & Lymphoma patients & \multirow[t]{2}{*}{ Task-oriented coping style } \\
\hline & & & 11.67 & 60.98 & 93 & Leukemia patients & \\
\hline \multirow[t]{2}{*}{0.37} & \multirow[t]{2}{*}{198} & \multirow[t]{2}{*}{-0.890} & 11.57 & 37.84 & 107 & Lymphoma patients & \multirow[t]{2}{*}{ Emotion-oriented coping style } \\
\hline & & & 10.82 & 39.25 & 93 & Leukemia patients & \\
\hline \multirow[t]{2}{*}{0.47} & \multirow[t]{2}{*}{198} & \multirow[t]{2}{*}{-0.723} & 10.08 & 49.68 & 107 & Lymphoma patients & \multirow[t]{2}{*}{ Avoidance coping style } \\
\hline & & & 9.26 & 50.67 & 93 & Leukemia patients & \\
\hline \multirow[t]{2}{*}{0.15} & \multirow[t]{2}{*}{198} & \multirow[t]{2}{*}{-1.418} & 46.34 & 350.9 & 107 & Lymphoma patients & \multirow[t]{2}{*}{ Psychological wellbeing } \\
\hline & & & 42.42 & 359.9 & 93 & Leukemia patients & \\
\hline
\end{tabular}

Results of the above table show the differences in Lymphoma and Leukemia patients in coping styles, psychosocial adjustment and psychological wellbeing using independent $t$ test. Investigations show that there is not any significant difference between the two groups of patients in psychosocial adjustment variable. Because in the calculated t value (0.988), the significance level 0.32 is greater than 0.05 , the hypothesis is not supported and there is no significant difference between the two variables mean values. Further, there is no significant difference between the two groups in task-oriented coping styles. Because in the observed $t$ value $(0.446)$, the observed significance level $(0.65)$ is greater than 0.05 , the hypothesis is not supported and there is no significant difference between mean values. Moreover, there is no significant difference between the two groups of patients in emotion-oriented coping styles. Because in the observed $t$ value $(-0.890)$, the observed significance level $(0.37)$ is greater than 0.05 , the hypothesis is not supported and there is no significant difference between mean values. There is no significant difference between the two groups of patients in avoidant coping styles. Since in the observed t value $(-0.723)$, the observed significance value $(0.47)$ is greater than 0.05 , the hypothesis is not supported. Furthermore, there is no significant difference between the two groups of patients in psychological wellbeing variable. Because in the observed t value (-1.418), the observed significance level $(0.15)$ is greater than 0.05 , the hypothesis is not supported.

\section{Conclusion and Discussion}

Main hypothesis: "coping styles and psychological wellbeing can predict psychosocial adjustment in Lymphoma and 
Leukemia cancer patients." Results showed that coping styles and psychological wellbeing can predict psychosocial adjustment in Lymphoma and Leukemia patients. Therefore, research main hypothesis is supported. This result conforms to the results of studies conducted by Roni (2003) and Speigel (2011). One of the dimensions of psychological wellbeing is having close relationship with friends. It seems that confused relationships have indirect impacts on health. For instance, a confused individual is indifferent to his medicine dose but a calm patient pays more attention to his or her possible physical treatment. In fact, a calm life which is accompanied by constructive relationships and pacific problemsolving can reduce destructive tensions and conflicts and reduces anger and aggression.

First subsidiary hypothesis: "coping styles predict psychosocial adjustment in Lymphoma patients." Results showed that coping styles can predict 0.52 of variations in psychosocial adjustment. Therefore, it can be said that the hypothesis is supported. This result conforms to the results of studies conducted by Park and Gaffi (2007), Pakenham and Jim (2009), Zeinal and Sania (2010), Nada (2011), Clark (2013). Efficient coping styles like task-oriented style clarifies problems for patients. Considering cognitive approach to disease control, it can be said that selection of more efficient coping styles can increase adjustment to internal and external changes.

Second subsidiary hypothesis: "psychological wellbeing can predict psychosocial adjustment in Lymphoma cancer patients." Results showed that psychological wellbeing can predict 0.41 of variations in psychosocial adjustment. Therefore, it can be said that this hypothesis is verified. This result conforms to the results of studies conducted by Corita et al (2013) and Moriera and Canavaro (2013). One of the dimensions of psychological adjustment is self-acceptance. Self-acceptance means having a positive approach to oneself and accepting different positive and negative aspects.

Third subsidiary hypothesis: "coping styles can predict psychosocial adjustment in Lymphoma patients." Results showed that coping styles can predict 0.57 of variations in psychosocial adjustment. Therefore, this hypothesis is supported. This result conforms to the results of studies conducted by Kario and Hamin (2009) and Ocan and Stock (2009). Adoption of coping styles by patients can be resulted from patients' information about different dimensions of a disease. Acquisition of different information about a disease can facilitate treatment.

Fourth subsidiary hypothesis: "psychological wellbeing can predict psychosocial adjustment in Lymphoma patients." Results showed that psychological wellbeing can predict 0.508 of variations of psychosocial adjustment. Therefore, it can be said that this hypothesis is supported. This result conforms to the results of studies conducted by John Petit (2013) and Moriera and Malek (2011). One of the dimensions of psychological wellbeing is domination over environment. This means a sense of domination over environment, control of internal activities and effective use of opportunities. Predictability and controllability of stressful conditions can help confront stress and prevent from distress.

Fifth subsidiary hypothesis: "psychosocial adjustment, coping strategies and psychological wellbeing differ in Lymphoma and Leukemia patients." Results showed that there is no significant difference between the two groups in the three variables. Therefore, research hypothesis is not supported. The role of gender can be important in this case. Women use emotion-oriented methods to deal with life problems like diseases and try to establish balance between internal and external problems. This can be defined as psychological adjustment. Reef believes that wellbeing means an attempt for improvement and excellence which is fulfilled by talents and potentials. Coping styles are continuous attempt for adjusting individuals to imbalance. An individual's evaluation of tension and management is very important in this case. Results of this research can contribute to improvement of the role of dimensions of psychosocial adjustment in patients who suffer from Lymphoma and Leukemia cancer.

\section{References}

Akbarzadeh Pasha, Hojjatollah (2010). Blood and cancer. First edition, Tehran: Golban publications. Pp: 2-45.

Banki, Y; Abedin, A and Monirpour, N (2011). Investigation of the role of cognitive variables in depression of youths suffering cancer. Journal of medicine faculty, ShahidBeheshti University of medical Sciences and hygienic services, 35th period, number 3: 48-49.

Bayani, Ali Asghar; Goudarzi, Hoseiniye and MohamamdKoucheki, Ashour (2007). Relationship between psychological wellbeing dimensions and general health in students of Azadshahr Islamic Azad University. Journal of knowledge and research in applied psychology, spring and summer, 2007, 35: 153-164.

Clarke, S., Newell, R., Thompson, A., Harcourt D,. and Lindenmeyer, A.(2013). Appearance Concerns And Psychosocial Adjustment Following Head And Neck Cancer: A Cross-Sectional Study And Nine-Month Follow-Up. Clinical Psychology Unit, University of Sheffield,UK.

Derogatis, R. L., and Wise, Thomas N.(2002).Anxiety and depressive disorders in the chronic patients.Journal of Health Psychology, 9:13-29.

Ghoreishi Rad, Fakhrossadat. (2010). CISS test reliability. Andler and Parker. Journal of behavioral sciences, 4 (1): 1-7.

Kariv, D., and Heiman, T.(2009). Task-oriented versus emotion- oriented coping strategies: The case of college students. College Students Journal. 39(1):72-84 
Khodayarifard, M; Ghobari, B and ShokuhiYekta, M. (2010). Stress and coping styles in university students. Quarterly of psychological studies, 11 (3-4): 27-44.

Kurita, K., Garon, E. B., Stanton, A. L., and Meyerowitz, B. E.(2013). Uncertainty and psychological adjustment in patients with lung cancer.Psychooncology, (6):1396-401.

Malak, A. T., Gumus, A. B., and Cam, O.(2011). Relationships between psychosocial adjustment and hopelessness in women with breast cancer.Asian Pacific Journal of Cancer Prevention , 12(2):433-438.

Mikaeeli Mani, farzaneh (2009). Structural relationships between psychological wellbeing and emotional quotient, ability to control negative control and depression in mentally-retarded children's mothers and its comparison with normal children mothers. Journal of educational sciences, research in exceptional children area, number $92, \mathrm{p} 71$.

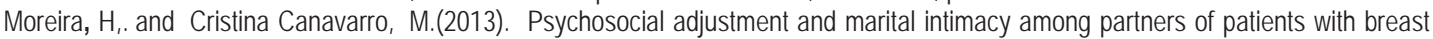
cancer.a comparison study with partners of healthy women. Journal of Psychosocial Oncology, Volume 31,282-304.

Muñoz-Eguiletal, A.(2007). Irrational beliefs as predictors of emotional adjustment after cancer.Journal of Rational-Emotive \& CognitiveBehavior Therapy, 25(1):1-15.

Okun, Morris. A., and Stock, William.A.(2009). Religion and subjective well-being among China's elderly population.Psychology and Aging, Vol 1(2), 91-102.

Pakenham, K., and Jim, L. R.(2009). Coping with multiple sclerosis.delevopment of a measure. JurnalOf Psychology, Health And Medicine, 6,411-428.

Park, L., and Gaffey, A. E.(2007). Relationships between psychosocial factors and health behavior changes in cancer survivors.An integrative review.Journal of Annals of Behavioral Medicine, a Publication of the Society of Behavioral Medicine (Ann Behav Med), 34(2), 115-134.

Peteet, John R.(2013). Spiritual perspective and religion in oncology.department of psychosocial oncology and palliative care. DanaFarber Cancer Institute, vol: 26,11.

Roini, C., Ottolini, F., Raffanelli, C., Tossani, E., Ryff, C. D., and Fave, A. G.(2003). The relationship of psychological well-being distress and personality.Psychotherapy Psychosomatics, 72, $268-375$.

Sheikh Nejad, Gholam Reza. (2011). What is cancer? Tehran: Daryaft publications. Pp: 22-53.

Spiegel, D., and Giese-Davis, J.(2011). Depression and cancer, mechanisms and disease progression. Journal of Biol Psychiatry, 54, 269-282.

Taghizadeh, M; Safarzadeh, M; and abolghasemBeik, A. (2013). Relationship between life quality, coping styles and worry about death in cancer survivors. Journal of international basic sciences and applied sciences studies, number 7 (3): 180-184.

Zainal, N. Z., and Saniah, A. R.(2010). Anxiety, depression and coping strategies in breast cancer patients on chemotherapy.Department of Psychological Medicine, Faculty of Medicine, Malaysia, Vol 19, № 2. 